\title{
Facile Synthesis of Magnetic Activated Carbon Composite for Arsenic Adsorption
}

\author{
Bivek Karki, Pragya Pandey ${ }^{1}$, Rinita Rajbhandari², Sahira Joshi ${ }^{2}$, Agni Raj Koirala ${ }^{3}$, \\ Ram Kumar Sharma ${ }^{2,4}$, Hem Raj Pant ${ }^{1,4 *}$ \\ 'Nano-materials Lab, Material Science and Engineering Program, Department of Applied Sciences, \\ Pulchowk Campus, IOE, Tribhuvan University, Nepal \\ ${ }^{2}$ Department of Applied Sciences, Pulchowk Campus, IOE, Tribhuvan University, Nepal \\ ${ }^{3}$ Korea Center for Artificial Photosynthesis, Center for Nanomaterials, Department of Chemistry, \\ Sogang University, Seoul 121-742, Republic of Korea \\ ${ }^{4}$ Research Institute for Next Generation, Kalanki, Kathmandu, Nepal \\ *Corresponding author: hempant@ioe.edu.np
}

Received: Dec 11, 2018

Revised: Feb 19, 2019

Accepted: Feb 22, 2019

\begin{abstract}
Porous activated carbon (AC) and magnetic iron oxide nanoparticles (NPs) are widely used for the removal of arsenic from water body. Fabrication of composite material of iron oxide NPs on the surface of porous AC can further enhance this activity for commercial application. In this research, a magnetic AC composite for arsenic adsorption was prepared by facile hydrothermal treatment of aqueous solution containing activated carbon obtained from lapsi seed stone, iron(II) chloride, polyvinylpyrrolidone (PVP) and ethanol. Several analytical techniques such as scanning electron microscopy (SEM), energy dispersive $\mathrm{x}$-ray (EDX), X-ray diffraction (XRD) and Fourier-transform infrared spectroscopy (FTIR) confirmed the formation of magnetite $\left(\mathrm{Fe}_{3} \mathrm{O}_{4}\right)$ nanoparticles on the surface of porous AC. The prepared materials were accessed for their arsenic adsorption capacity using arsenic (III) trioxide solution and found that composite $\mathrm{Fe}_{2} \mathrm{O}_{3} / \mathrm{AC}$ can remove the arsenic from water far more effectively than activated carbon alone. For 0.5 $\mathrm{g} / \mathrm{ltr}$ loading of composite sample with contract time of 5 hours, the arsenic content was significantly reduced, which shows that as-fabricated composite can be used potentially for water treatment.
\end{abstract}

Keywords: Activated carbon, Adsorption, Arsenic, Hydrothermal treatment, Magnetite.

\section{Introduction}

Arsenic has been creating potentially serious environmental problems for humans as well as other living organisms throughout the world. Coagulation of protein, formation of complexes with coenzymes and inhibition of adenosine triphosphate (ATP) production during respiration are some of the health hazards brought about by arsenic [7]. Most of the reported arsenic problems are found in groundwater water supply systems and are caused by both natural and artificial processes. Mineral weathering and dissolution resulting from a change in the geo-chemical environment to a reductive condition are the possible natural causes for arsenic contamination of water. While human activities like mining wastes, petroleum refining products, sewage sludge, agricultural chemicals, 
ceramic manufacturing industries and coal fly ash can be considered as some of the major causes of arsenic contamination [14]. Recently, one of the major challenges in developing countries is the removal of toxic metals from water. The methods such as chemical precipitation [17, 19], solvent extraction [2], ion exchange [8], reverse osmosis and adsorption [18] have been adopted to remove the heavy metal ions from water. Among these techniques adsorption with suitable adsorbent is the mostly used method. Powdered activated carbon has been used as water treatment agent for quite a long time and with great efficiency as it has high adsorption rate and capacity for various organic pollutants and is also inexpensive. But AC alone is not very effective when it comes to removal of arsenic from water. The synthesis of magnetic carbon adsorbent by integrating magnetic particles with powdered activated carbon has gained increasing attention worldwide. Various literatures have shown that the hydrous ferric oxide (HFO)/magnetite nano particles (MNP) form of iron has a high capacity to remove both arsenite and arsenate, compared to other conventional adsorption media in practice [13]. Arsenic adsorption onto iron-tailored AC is considered to be a promising treatment technology because it is economical and easy to set up. AC can also act as a protective structure to support the otherwise fragile granular iron media [12]. There are several methods of arsenic removal techniques that are in practice today. Combination of oxidation and precipitation, nano filtration and ion exchange and adsorption are some of the popular methods for removal of arsenic from water.

The most frequently used magnetic particle is iron oxide, especially magnetite [15]. Iron (III) has a great affinity toward inorganic arsenic species and it is very selective in the sorption process [6]. The aqueous oxyanions (such as $\mathrm{H}_{2} \mathrm{AsO}_{4}$ or $\mathrm{HAsO}_{4}^{2-}$ ) undergo a ligand exchange reaction with iron speciation on the carbon surface and form an inner-sphere mono-dentate or bi-dentate surface complex [9,11]. The amount of arsenic removed is closely related both to the amount of iron loaded, and to the dispersion and surface accessibility of this iron within the activated carbon [5]. Therefore, we have developed a simple strategy to decorate $\mathrm{Fe}_{2} \mathrm{O}_{3} \mathrm{NPs}$ on the surface of porous AC carbon by facile hydrothermal treatment of iron oxide precursor solution. Hydrothermal processing can be defined as any heterogeneous reaction in the presence of aqueous solvents or mineralizers under high pressure and temperature conditions to dissolve and recrystallize materials that are relatively insoluble under ordinary conditions [4]. Due to its various advantages in processing of nano materials for wide range of applications, hydrothermal technique is becoming one of the major tools for advanced material processing [22]. Various composites like Ag-iron oxide/fly ash [16], $\mathrm{Ag}-\mathrm{ZnO} / \mathrm{g}-\mathrm{C}_{3} \mathrm{~N}_{4}$ [1] and $\mathrm{Ag}-\mathrm{ZnO} /$ reduced graphene oxide [20] have been successfully synthesized using simple one pot hydrothermal approach

\section{Experimental}

\subsection{Materials}

The activated carbon prepared from lapsi seed powder [21] was used for the fabrication of composite material. Iron chloride tetra hydrate $\left(\mathrm{FeCl}_{2} \cdot 4 \mathrm{H}_{2} \mathrm{O}\right.$ ) (Samchun Chemicals), ammonium hydroxide $\left(\mathrm{NH}_{4} \mathrm{OH}, 25 \% \mathrm{NH}_{3}\right.$ in water) (Fisher Scientific), arsenic trioxide $\left(\mathrm{As}_{2} \mathrm{O}_{3}\right)$ (G.S. Chemical Testing $\mathrm{Lab}$ and Allied Industries), potassium hydroxide $(\mathrm{KOH})$ (Fisher Scientific), sulphuric acid $\left(\mathrm{H}_{2} \mathrm{SO}_{4}\right)$ (Fisher Scientific) and polyvinylpyrrolidone (PVP, MW-5800) (Alfa Aesar) were used as received for this study. 


\subsection{Preparation of Fe/AC Composite}

A one step hydrothermal approach was followed for the fabrication of magnetic activated carbon composite. The sample was prepared by dissolving $400 \mathrm{mg}$ of $\mathrm{FeCl}_{2} \cdot 4 \mathrm{H}_{2} \mathrm{O}$ and $10 \mathrm{mg}$ of PVP in 20 $\mathrm{ml}$ of distilled water and $1 \mathrm{ml}$ of ammonia solution was added to this solution with constant stirring for 45 minutes using magnetic stirrer. The solution containing $50 \mathrm{mg} \mathrm{AC}$ in $10 \mathrm{ml}$ of distilled water and $5 \mathrm{ml}$ of ethanol was added to the former solution. The mixture was then transferred to autoclave for hydrothermal treatment at $130^{\circ} \mathrm{C}$ for 3 hours. After cooling at room temperature, the obtained product was filtered and washed repeatedly with distilled water and ethanol and was dried in oven at $30^{\circ} \mathrm{C}$ for 12 hours and at $80^{\circ} \mathrm{C}$ for 6 hours. The process was repeated for different weight proportions of $\mathrm{FeCl}_{2} \cdot 4 \mathrm{H}_{2} \mathrm{O}$.

\subsection{Characterization}

The surface morphology and composition of as-synthesized particles were studied by filedemission scanning electron microscopy (FE-SEM, S-7400, Hitachi, Japan) and energy dispersive $\mathrm{x}$-ray analysis (EDX). Information about the crystallographic structure of as-synthesized composite and pristine $\mathrm{AC}$ was obtained using Rigaku x-ray diffractometer (XRD, Rigaku, Japan) with $\mathrm{Cu}$ $\mathrm{K} \alpha(\lambda=1.540 \AA)$ radiation over Bragg angles ranging from 5 to $90^{\circ}$. Fourier transform infrared (FT-IR) spectra of different samples were recorded by using an ABB Bomen MB100 spectrometer (Bomen, Canada).

\subsection{Preparation of Arsenic Stock Solution}

500 ppm stock solution of arsenic was prepared by using arsenic trioxide $\left(\mathrm{As}_{2} \mathrm{O}_{3}\right)$. 15\% potassium hydroxide $(\mathrm{KOH})$ solution was prepared by dissolving $1.6 \mathrm{~g}$ of $\mathrm{KOH}$ pellets in $9 \mathrm{ml}$ distilled water and $0.165 \mathrm{~g}$ of $\mathrm{As}_{2} \mathrm{O}_{3}$ was added to it and allowed to dissolve. The solution was then neutralized with $1 \mathrm{~N}$ sulphuric acid $\left(\mathrm{H}_{2} \mathrm{SO}_{4}\right)$ and $3 \mathrm{ml}$ excess of $\mathrm{H}_{2} \mathrm{SO}_{4}$ was added to make the solution acidic. The solution was then diluted to $250 \mathrm{ml}$. The solution was then diluted to adjust the concentration to $2 \mathrm{ppm}$ by serial dilution which was then treated with the prepared $\mathrm{AC}$ and its composite.

\subsection{Arsenic Adsorption Test}

The standard silver diethyldithiocarbamate/(SDDC, 3500-As, C) method as defined by American Public Health Association (APHA) was deployed to know the concentration of arsenic in water before and after treatment with the prepared composite sample. In this method, inorganic arsenic present in sample was reduced to arsine $\left(\mathrm{AsH}_{3}\right)$ by zinc in acid solution in an arsenic generator. The arsine was passed through a delivery tube containing filter paper impregnated with lead acetate solution and into an absorber tube containing silver diethyldithiocarbamate dissolved in chloroform. In the absorber, arsenic reacts with the silver salt, forming a soluble red complex whose photometric determination was conducted at $510 \mathrm{~nm}$ using UV/visible spectrophotometer (CECIL CE2041).

\section{Results and Discussion}

\subsection{Characterization of the Composite Particles}

The surface morphologies of pristine activated carbon and iron oxide nanoparticles doped activated 
carbon were investigated using FE-SEM analysis. Fig.1 shows the respective morphologies of pristine AC and iron oxide/AC composite. The FE-SEM images of composite demonstrate that rod shaped magnetite nanoparticles of diameter of about $50 \mathrm{~nm}$ have been formed on the surface of porous activated carbon.
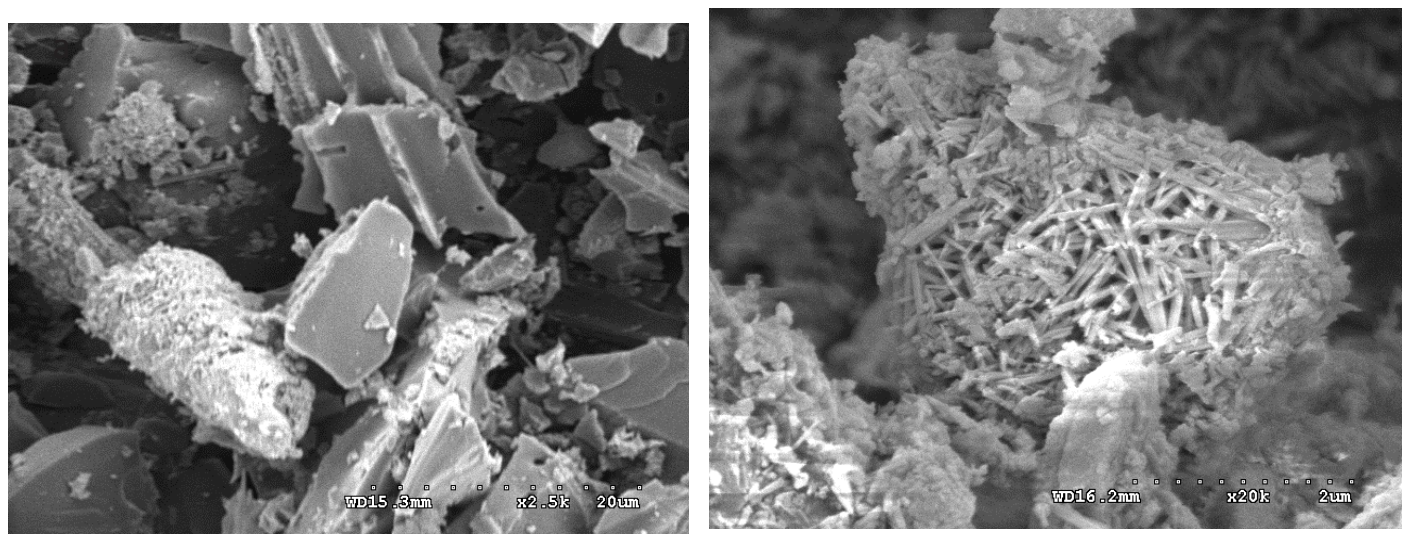

Fig. 1: FE-SEM image of pristine AC (a) and iron oxide/AC composite (b)

SEM-EDX analysis was performed to examine the composition of the fabricated composite material which confirmed that the nano particles deposited were of iron oxide as shown in Fig.2. The formation of composite was further confirmed by FT-IR spectroscopy. Fig. 3 shows the FTIR spectra of pristine $\mathrm{AC}$ and iron oxide/AC composite. The composite sample showed a wide band at $3300 \mathrm{~cm}^{-1}$ which can be assigned to stretching mode of adsorbed water molecules $[16,10]$. The corresponding band is not visible in pristine AC sample which can be accounted for the presence of more hygroscopic magnetite particles. Another adsorption band can be seen in the IR spectra of composite material at $570 \mathrm{~cm}^{-1}$ which can be assigned as the analytical band of magnetite [3, 16]. Hence from the IR spectroscopy it can be concluded that the nano particles of magnetite have grown on the surface of $\mathrm{AC}$ after hydrothermal treatment.
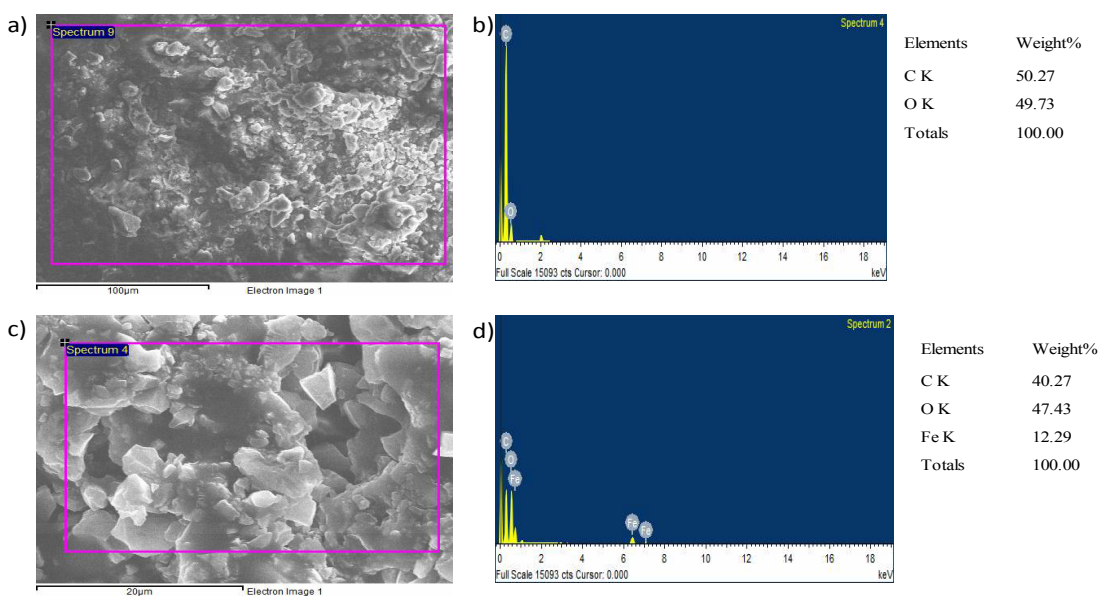

Fig. 2: SEM-EDX of pristine $\mathrm{AC}(\mathrm{a}, \mathrm{b})$ and $\mathrm{Fe}_{3} \mathrm{O}_{4} / \mathrm{AC}$ composite (c, d) 


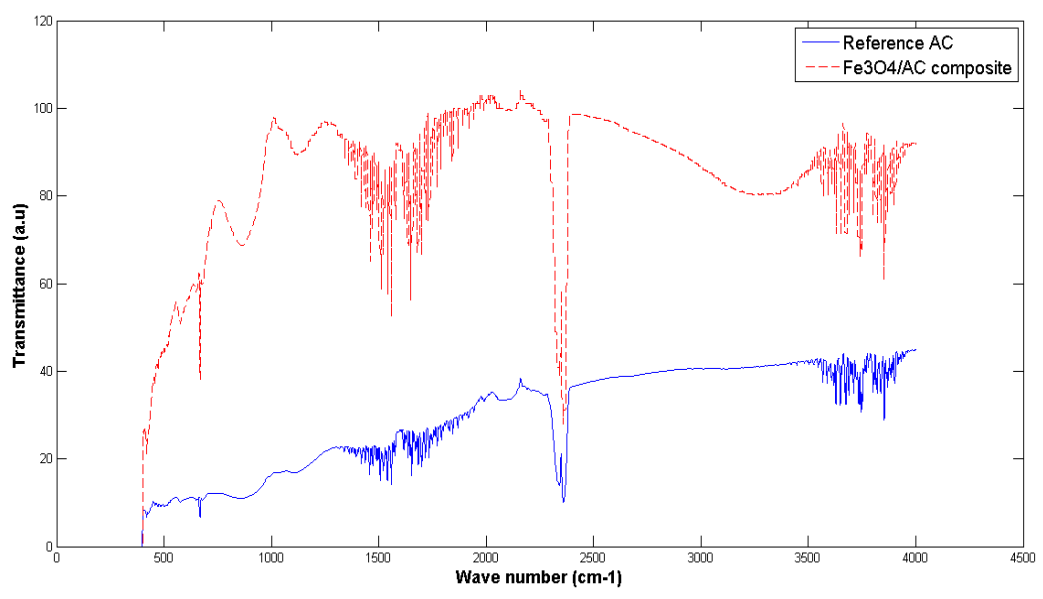

Fig. 3: FT-IR spectra of pristine $\mathrm{AC}$ and $\mathrm{Fe}_{3} \mathrm{O}_{4} / \mathrm{AC}$ composite

Furthermore, XRD analysis was performed to determine the crystal structure of the synthesized composite. Fig. 4 shows the XRD pattern of pristine AC and the prepared iron oxide/AC composites with corresponding $2 \theta$ values. The XRD graph for the composite sample shows strong and sharp peaks indicating that the synthesized product has well developed crystallinity when compared to XRD graph of pristine AC sample. The XRD pattern for pristine AC sample shows broad peak at diffraction angle (20) $25^{\circ}$. This peak can be indexed to amorphous carbon20. Similarly, the main peaks at diffraction angle of $35.80^{\circ}, 43.50^{\circ}, 53.70^{\circ}, 57.30^{\circ}$ and $74.20^{\circ}$ are of $\mathrm{Fe}_{3} \mathrm{O}_{4}$ [16]. Hence $\mathrm{XRD}$ analysis shows that the hydrothermal treatment resulted in the growth of magnetite nano particles on $\mathrm{AC}$ also increasing the crystallinity of the composite.

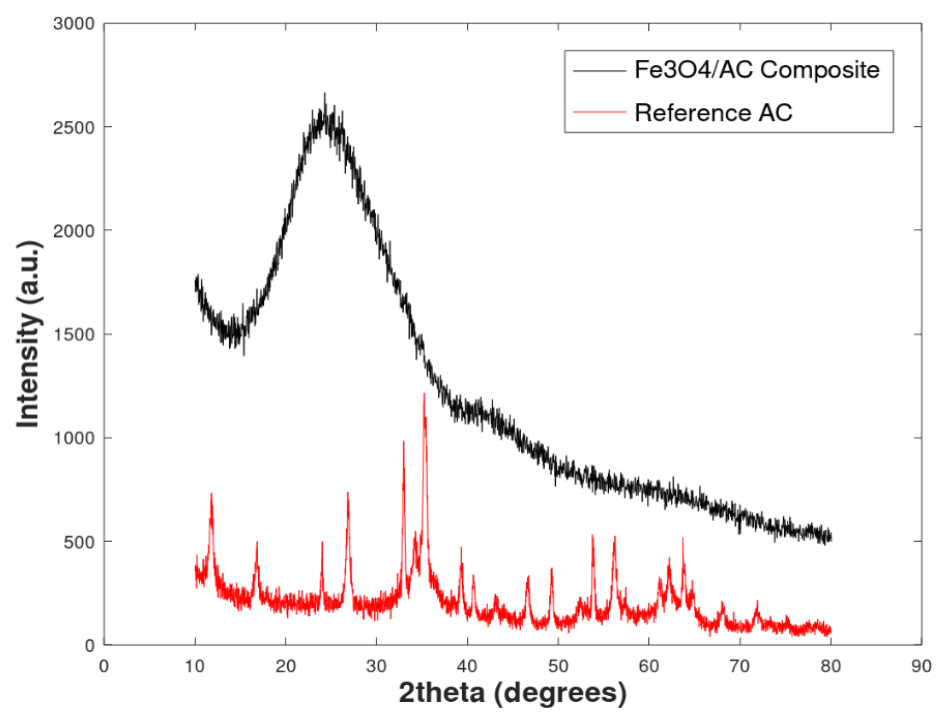

Fig. 4: XRD patterns of pristine $\mathrm{AC}$ and $\mathrm{Fe}_{3} \mathrm{O}_{4} / \mathrm{AC}$ composite 


\subsection{Arsenic Adsorption}

The prepared $500 \mathrm{ppm}$ arsenic stock solution was diluted to $2 \mathrm{ppm}$ by serial dilution. The prepared $2 \mathrm{ppm}$ solution was then distributed in two glass bottles with $100 \mathrm{ml}$ each. The $\mathrm{pH}$ of the solution prepared was measured to be $2.3 .50 \mathrm{mg}$ of pure $\mathrm{AC}$ was added into one bottle and $50 \mathrm{mg}$ of $\mathrm{Fe}_{3} \mathrm{O}_{4} / \mathrm{AC}$ composite was added to another bottle and stirred for 5 hours. Each solution was then filtered and the filtrate was collected in clean glass bottles and tested for arsenic content. The result obtained after SDDC test is shown in Fig. 5. The result showed that after 5 hours treatment with $50 \mathrm{mg}$ of synthesized composite in $100 \mathrm{ml}$ of arsenic the arsenic concentration was reduced to $690 \mathrm{ppb}$ from $2000 \mathrm{ppb}$ while the concentration in the solution treated with $\mathrm{AC}$ was dropped down to just $1420 \mathrm{ppb}$. The result indicates that $\mathrm{Fe}_{3} \mathrm{O}_{4} / \mathrm{AC}$ composite is far more superior in removal of arsenic from water than the conventional $\mathrm{AC}$ alone because its high isoelectric point (IEP=8.1) and selectivity for arsenic [13].

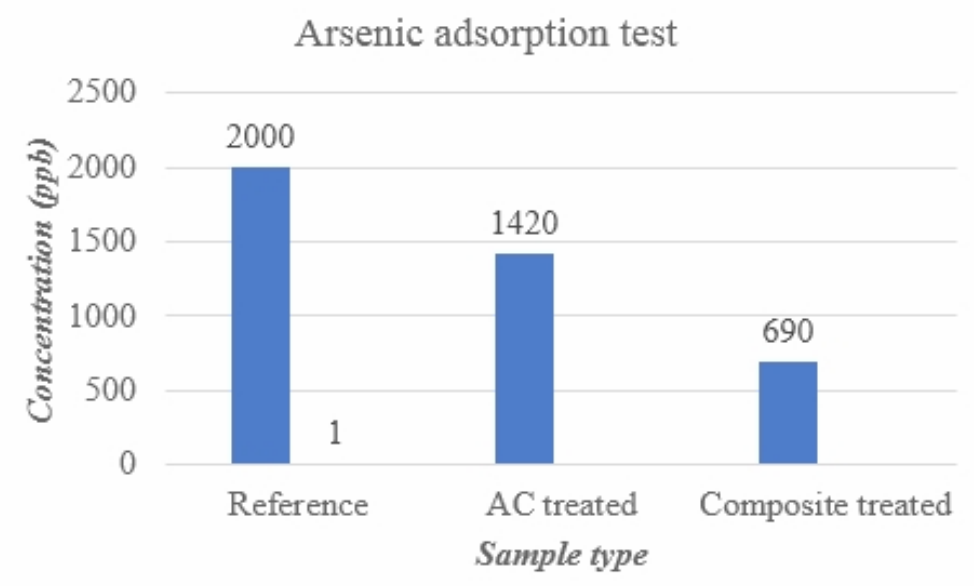

Fig. 5: Arsenic adsorption test of pristine $\mathrm{AC}$ and $\mathrm{Fe}_{3} \mathrm{O}_{4} / \mathrm{AC}$ composite

\section{Conclusion}

In summary, a magnetically separable and stable $\mathrm{Fe}_{3} \mathrm{O}_{4} / \mathrm{AC}$ composite was synthesized using one pot facile hydrothermal treatment. Furthermore, it is reported that the temperature of the hydrothermal treatment was significant in determining the grown of nano iron oxide particles. Activated carbon (AC) obtained from agricultural waste materials are potential for cost effective adsorption media. Macro and meso pores in activated carbon can serve a suitable adsorption site and also provided large surface area for the deposition of magnetite nano particles. The $\mathrm{Fe}_{3} \mathrm{O}_{4} / \mathrm{AC}$ composite displayed excellent efficiency in removal of arsenic from water. The presented protocol for the synthesis of the composite product is simple, fast, environmentally friendly, cheap and yet very efficient and effective.

Acknowledgment: The research work was supported by The World Academy of Science, Trieste, Italy (TWAS)/Swedish International Development Corporation Agency (Sida) (project number; 18168RG/ CHE/AS_G-FR3240303651) and University Grant Commission, Nepal (project number; -CRG-74/74Engg-02). We are thankful to Department of Chemistry, Sogang University, Republic of Korea for characterizing the samples. 


\section{References}

[1] Adhikari SP, Pant HR, Kim JH, Kim HJ, Park CH and Kim CS (2015), One pot synthesis and characterization of Ag-ZnO/g-C3N4 photocatalyst with improved photoactivity and antibacterial properties, Colloids and Surfaces A: Physicochemical and Engineering Aspects, 482: 477-484.

[2] Batchu NK, Sonu CH and Lee MS (2014), Solvent extraction equilibrium and modeling studies of manganese from sulfate solutions by a mixture of Cyanex 301 and TBP, Hydrometallurgy, 144: $1-6$.

[3] Betancur AF, Pérez FR, Correa MDM and Barrero CA (2012), Quantitative approach in iron oxides and oxihydroxides by vibrational analysis, Opt. Pura Apl, 45: 269-275.

[4] Byrappa K and Adschiri T (2007), Hydrothermal technology for nanotechnology, Progress in crystal growth and characterization of materials, 53(2): 117-166.

[5] Chen W, Parette R, Zou J, Cannon FS and Dempsey BA (2007), Arsenic removal by ironmodified activated carbon, Water research, 41(9): 1851-1858.

[6] Deliyanni EA, Bakoyannakis DN, Zouboulis AI and Matis KA (2003), Sorption of As (V) ions by akaganeite-type nanocrystals, Chemosphere, 50(1): 155-163.

[7] Duruibe JO, Ogwuegbu MOC and Egwurugwu JN (2007), Heavy metal pollution and human biotoxic effects, International Journal of physical sciences, 2(5): 112-118.

[8] Franco PE, Veit MT, Borba CE, da Cunha Gonçalves G, Fagundes-Klen MR, Bergamasco R and Suzaki PYR (2013), Nickel (II) and zinc (II) removal using Amberlite IR-120 resin: Ion exchange equilibrium and kinetics, Chemical engineering journal, 221: 426-435.

[9] Fuller CC, Davis JA and Waychunas GA (1993), Surface chemistry of ferrihydrite: Part 2. Kinetics of arsenate adsorption and coprecipitation, Geochimica et Cosmochimica Acta, 57(10): 2271-2282.

[10] Gotić M and Musić S (2007), Mössbauer, FT-IR and FE SEM investigation of iron oxides precipitated from FeSO4 solutions, Journal of Molecular Structure, 834: 445-453.

[11] Grossl PR, Eick M, Sparks DL, Goldberg S and Ainsworth CC (1997), Arsenate and chromate retention mechanisms on goethite. 2. Kinetic evaluation using a pressure-jump relaxation technique, Environmental Science \& Technology, 31(2): 321-326.

[12] Jang M, Chen W and Cannon FS (2008), Preloading hydrous ferric oxide into granular activated carbon for arsenic removal, Environmental science \& technology, 42(9): 3369-3374.

[13] Jang M, Min SH, Kim TH and Park JK (2006), Removal of arsenite and arsenate using hydrous ferric oxide incorporated into naturally occurring porous diatomite, Environmental science \& technology, 40(5): 1636-1643.

[14] Jang M, Shin EW and Park JK (2002), Removal of Arsenic Using Mesoporous Silicate Media Impregnated Metal Oxides Nano-Particles, Proceedings of the Water Environment Federation, 13: $40-54$.

[15] Jiuhui QU (2008), Research progress of novel adsorption processes in water purification: a review, Journal of environmental sciences, 20(1): 1-13.

[16] Joshi MK, Pant HR, Liao N, Kim JH, Kim HJ, Park CH and Kim CS (2015), In-situ deposition of silver- iron oxide nanoparticles on the surface of fly ash for water purification, Journal of colloid and interface science, 453: 159-168.

[17] Maldonado-Reyes A, Montero-Ocampo C and Solorza-Feria O (2007), Remediation of drinking water contaminated with arsenic by the electro-removal process using different metal electrodes, Journal of Environmental Monitoring, 9(11): 1241-1247. 
[18] Mohan S and Gandhimathi R (2009), Removal of heavy metal ions from municipal solid waste leachate using coal fly ash as an adsorbent, Journal of Hazardous Materials, 169(1-3): 351-359.

[19] Navarro RR, Wada S and Tatsumi K (2005), Heavy metal precipitation by polycation-polyanion complex of PEI and its phosphonomethylated derivative, Journal of hazardous materials, 123(13): 203-209.

[20] Pant HR, Pant B, Kim HJ, Amarjargal A, Park CH, Tijing LD, and Kim CS (2013), A green and facile one-pot synthesis of $\mathrm{Ag}-\mathrm{ZnO} / \mathrm{RGO}$ nanocomposite with effective photocatalytic activity for removal of organic pollutants, Ceramics International, 39(5): 5083-5091.

[21] Rajbhandari R, Shrestha LK, Pokharel BP and Pradhananga RR (2013), Development of Nanoporous Structure in Carbons by Chemical Activation with Zinc Chloride, Journal of nanoscience and nanotechnology, 13(4): 2613-2623.

[22] Zhang F (2015), "Wet" Chemical Synthesis and Manipulation of Upconversion Nanoparticles, Photon Upconversion Nanomaterials, Springer, Heidelberg, Berlin. 